\title{
PERANCANGAN SISTEM PENGINGAT BERBASIS ANDROID MENGGUNAKAN GOOGLE MAPS DAN GPS
}

\author{
Indra Usmanan, Sumarsono, Dwi Nugraheny \\ Jurusan Teknik Informatika \\ Sekolah Tinggi Teknologi AdisutjiptoYogyakarta \\ informatika@stta.ac.id
}

\begin{abstract}
Human is perfect creation of God. Hower, the human ability in processing data in not as effective as computer, as long as the data is saved in the computer memory. By utilizing the computer, such as mobile phone based on android, Google Maps, and GPS, user can make application that can remind the agenda. At this case, the data that has been saved before can be used anytime when needed. This final repot is developed a remainder application based on android using Google Maps and GPS. This system use postgreSQL database the implanted in server. It makes the android smartphone that has been installed with the reminder application become a to client. As the result, the system has some feature. From these feature, the usres are expected to use Android smartphone to help remembering the activities agenda, whenever and wherever.
\end{abstract}

Keyword: Android, Reminder System, Google Maps, GPS

\section{Pendahuluan}

Perkembangan teknologi semakin pesat dan cepat, khususnya teknologi informasi dan komunikasi. Hal ini membuat manusia bagaikan tak terpisah oleh jarak ruang dan waktu. Dengan perkembangan teknologi yang kian maju, manusia dapat membuat berbagai macam peralatan sebagai alat bantu dalam menjalankan berbagai aktifitas untuk mendukung produktifitas. Dimana hampir semua bidang dapat memanfaatkan teknologi komputerisasi untuk mempermudah dalam menyelesaikan semua aktifitas pekerjaan. Memang dapat dirasakan manfaat dan keuntungan yang diperoleh, karena kecanggihan dalam pengoperasian komputer ataupun dalam penanganan komputer.

Seiring dengan tingkat mobilitas yang tinggi, beberapa tahun terakhir tengah marak perangkat bergerak atau mobile device. Salah satu perangkat mobile yang paling pesat adalah handphone dimana hampir setiap orang memilikinya. Handphone yang sedianya sebagai alat komunikasi, saat ini sudah lebih dari fungsi dasarnya. Berbagai macam fitur telah ditanamkan, seperti pengolah gambar dan video, pengolah dokumen dan lain sebagainya. Hal ini tak lepas dari penggunaan sistem operasi pada handphone. Layaknya pada komputer, handphone pun dapat di install berbagai macam aplikasi yang diinginkan.

Pemanfaatan perangkat mobile phone sebagai pendamping dalam melaksanakan kegiatan sehari-hari sudah sangat lumrah bagi sebagian orang. Hal ini dikarenakan beberapa mobile phone sudah memiliki fungsi dan kemampuan lebih dari sekedar fungsi dasarnya. Android sebagai sistem operasi yang dapat ditanamkan pada perangkat handphone memiliki kemampuan untuk dapat diinstall aplikasi-aplikasi yang diperlukan oleh pengguna.

Manusia adalah ciptaan Tuhan yang sempurna, namun kemampuan manusia dalam mengelola data tidak seefektif seperti computer yang bisa selama data tersebut masih 
tersimpan di memory computer maka selama itu pula data dapat di proses. Berbeda dengan manusia yang sering lupa dalam menyimpan data, kecuali data tersebut ditulis di kertas (diary) dan disimpan, sehingga kurang akurat dan efisien. Dengan memanfaatkan kecanggihan computer seperti mobile phone yang berbasis android, google maps, dan gps dapat dibuat sebuah aplikasi yang dapat mengingat agenda dalam hal ini data yang telah disimpan sebelumnya sehingga sewaktu-waktu bermanfaat jika diperlukan.

\section{Landasan Teori}

\subsection{Android}

Android adalah kumpulan perangkat lunak yang ditujukan bagi perangkat bergerak mencakup sistem operasi, middleware, dan aplikasi kunci. Android Standart Development Kid (SDK) menyediakan perlengkapan dan Application Programming Interface $(A P I)$ yang diperlukan untuk mengembangkan aplikasi pada platform android menggunakan bahasa pemrograman java.

\subsection{PostgreSQL}

PostgreSQL merupakan DMS Server Open PostgreSQL sering disebut juga posgres merupakan salah satu dari sejumlah database besar yang menawarkan skabilitas, keluwesan, dan kinerja yang tinggi penggunaanya begitu meluas di berbagai platform dan didukung oleh banyak bahasa pemrograman.

Perbedaan penting antara Postgres dengan sistem relasional standar adalah arsitektur Postgres yang memungkinkan user untuk mendefinisikan sendiri SQLnya, terutama pada pembuatan function atau biasa disebut sebagai stored procedure. Hal ini dimungkinkan karena informasi yang disimpan oleh Postgres bukan hanya tabel dan kolom, melainkan tipe, fungsi, metode akses, dan banyak lagi yang terkait dengan tabel dan kolom tersebut. Semuanya terhimpun dalam bentuk class yang bisa diubah oleh user. Arsitektur yang menggunakan class ini lazim disebut sebagai object oriented.

\subsection{Google Maps}

Google Maps adalah peta online atau membuka peta secara online. Sekarang dapat dilakukan secara mudah melalui servis gratis dari Google ini. Bahkan, servis ini menyediakan API (Application Programming Interface) yang memungkinkan developer lain untuk memanfaakan aplikasi ini di aplikasi buatannya. Tampilan Google Maps pun dapat dipilih berdasarkan foto asli atau peta gambar rute saja. Mengikuti perkembangan setiap pengguna yang mungkin sebelum dengan Google Maps terbatas yaitu belum ada seluruh detail dalam allokasi.

\subsection{GPS (Global Positioning System)}

GPS adalah sebuah system navigasi berbasiskan radio yang memberikan informasi posisi koordinat, kecepatan, dan waktu kepada pengguna di seluruh dunia. Jasa penggunaan satelit GPS tidak dikenakan biaya. Pengguna membutuhkan GPS receiver untuk dapat mengetahui koordinat lokasi. Keakuratan koordinat lokasi tergantung pada tipe GPS receiver. GPS terdiri dari tiga bagian yaitu satelit yang mengorbit bumi stasiun pengendali dan pemantau di bumi, 
dan GPS receiver (alat penerima GPS). Satelit GPS dikelola oleh Amerika Serikat. Alat penerima GPS inilah yang dipakai oleh pengguna untuk melihat koordinat posisi. Selain itu GPS juga berfungsi untuk menentukan waktu.

\section{Analisa Kebutuhan dan Perancangan Sistem}

\subsection{Spesifikasi Kebutuhan Hardware dan Software}

Spesifikasi kebutuhan hardware dan software untuk perancangan aplikasi ini terdiri dari beberapa macam yaitu :

\subsubsection{Spesifikasi Hardware}

Pembuatan aplikasi ini hardware atau perangkat keras merupakan semua peralatan fisik komputer. Sistem perangkat keras yang digunakan dalam pembuatan sistem ini adalah sebagai berikut :

1. Processor Intel Pentium Dual Core

2. RAM 1GB

3. Harddisk $160 \mathrm{~GB}$

4. Keyboard dan mouse standar

5. Handphone samsung Andriod froya 2.2

6. Memory eksternal hanphone

\subsubsection{Spesifikasi Software}

Dalam pembuatan aplikasi ini, spesifikasi software atau perangkat lunak yang digunakan adalah:

1. Sistem operasi yang digunakan adalah windows

2. Bahas pemograman yang digunakan adalah java

3. Database yang digunakan adalah postgreeSQL

4. Jdk-6u22-windows-i586 sebagai java environment java compiler di sistem operasi personal computer berbasis windows.

5. Intellij IDEA sebagai editor untuk development program berbasis java

6. Handphone mempunyai GPS

\subsection{Perancangan}

Tahap ini dibuat berdasarkan hasil dari tahap analisis. Dalam tahap ini terdapat tiga aksi yaitu activity diagram (diagram aktifitas), perancangan database dan perancangan tampilan antar muka (interface) aplikasi.

\subsection{Perancangan Diagram Use Case}

Agar aplikasi berfungsi dapat mengingat semua data yang telah di inputkan oleh user, maka user harus mengikuti prosedur yang telah diterapkan oleh aplikasi 


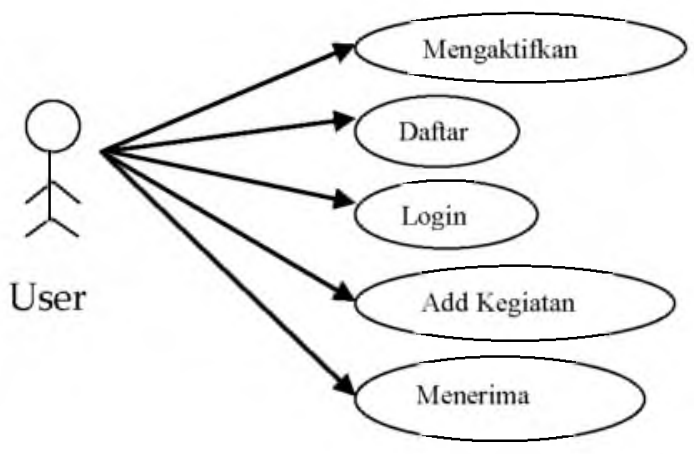

Pada diagram use case di jelaskan bahwa pada saat menggunakan aplikasi GPSremember U190 user terlebih dahulu mengaktifkan GPS kemudian daftar, login, kemudian user bisa melakukan add kegiatan di menu utama. Kemudian server secara otomatis menyimpan data tersebut, yang nantinya data tersebut diterima kembali oleh user.

Melakukan pengaturan untuk pengingat, maka aplikasi akan secara otomatis memberikan penanda berupa pesan. Ketika pengguna menjalankan use case tambah kegiatan, maka GPS memberikan informasi kepada sistem tentang nilai latitude dan longitude user berada. Dari data ini akan diolah database, aplikasi menunjukkan sesuai dengan lokasi dan posisi $u$ ser berada.

\section{Implementasi Dan Pengujian}

Untuk dapat menggunakan aplikasi GPSremember IU90 ini diperlukan smartphone berbasis android yang terhubung dangan internet sehingga dapat mengakses database yang telah ada. Setelah terpenuhi itu semua maka pengguna dapat memanfaatkan fitur yang ada, antara lain :

1. Form login

Halaman ini digunakan pengguna untuk mengakses aplikasi GPSremember IU90

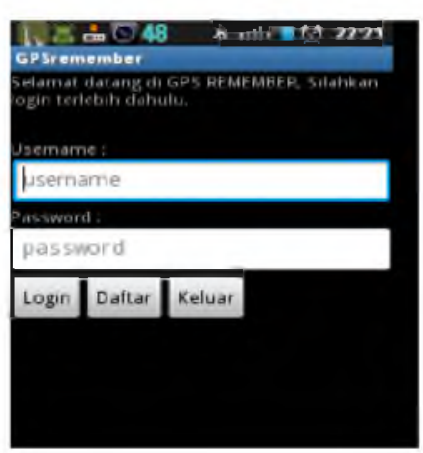

Gambar 1 Login

2. Menu Daftar

Menu ini digunakan untuk daftar sebagai member GPSremember IU90 


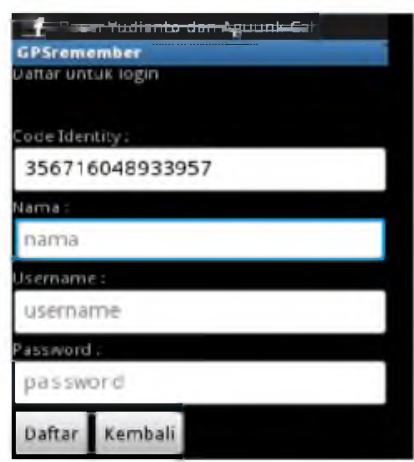

Gambar 2 Pendaftaran

3. Menu Add

Pada menu ini add digunakan untuk untuk menginputkan nama kegiatan, tempat, dan kegiatan.

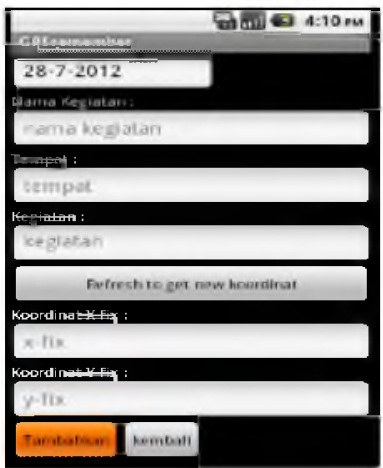

Gambar 3 Memasukan kegiatan

4. Menu List

Menu ini digunakan untuk melihat list kegiatan yang telah di inputkan pada menu add.

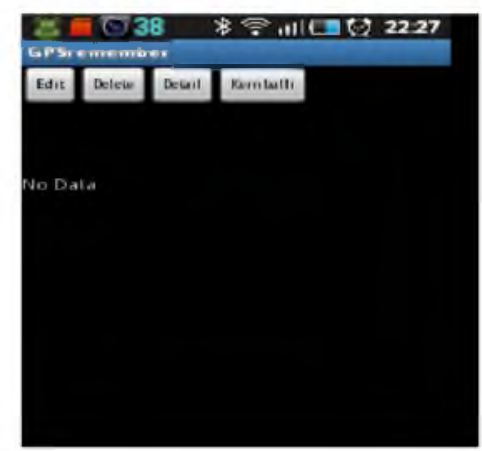

Gambar 4 Menu list

5. Form Tampilan Pesan

Pada form ini adalah tampilan Pesan yang akan tampil di layar smartphone 


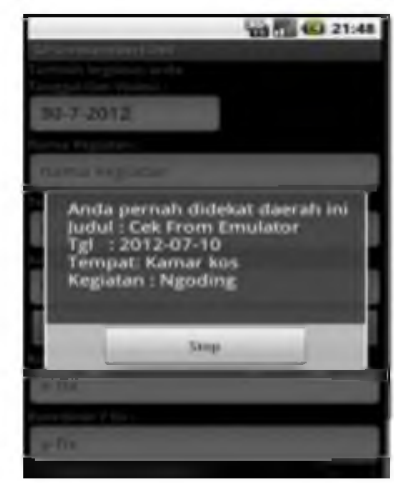

Gambar 5 Tampilan pesan

\section{Pengujian}

Pengujian sistem dilakukan dengan dua cara yaitu pengujian yang dilakukan secara objektif dengan format kuesioner seperti dijelaskan pada tabel 1

Tabel 1 Hasil pengujian kuesioner user

\begin{tabular}{|c|l|c|c|c|}
\hline No. & Pertanyaan & \multicolumn{3}{|c|}{ Penilaian } \\
\cline { 3 - 5 } & & Baik & Cukup & Kurang \\
\hline 1 & $\begin{array}{l}\text { Tampilan } \\
\text { Aplikasi }\end{array}$ & 19 & 9 & 2 \\
\hline 2 & $\begin{array}{l}\text { Kemudahan } \\
\text { Dalam } \\
\text { Pengaksesan }\end{array}$ & 14 & 14 & 2 \\
\hline 3 & $\begin{array}{l}\text { Kecepatan } \\
\text { Memproses } \\
\text { Data }\end{array}$ & 8 & 20 & 2 \\
\hline 4 & $\begin{array}{l}\text { Ketepatan } \\
\text { Menampilkan } \\
\text { Pesan }\end{array}$ & 16 & 10 & 4 \\
\hline \multicolumn{1}{|c|}{ Total } & 57 & 53 & 10 \\
\hline \multicolumn{2}{|l}{ Persentase } & $47,5 \%$ & $44,1 \%$ & $8,4 \%$ \\
\hline
\end{tabular}

\section{Kesimpulan}

Beberapa kesimpulan yang diambil dari hasil uji coba aplikasi ini antara lain adalah sebagai berikut :

1. Sistem GPSremember IU90 ini dapat berjalan apabila user maupun server terkoneksi internet dan user melakukan registrasi sebagai syarat menggunakan aplikasi.

2. Sistem GPSremember IU90 memudahkan pengguna untuk mendapatkan informasi yang lebih efisien dalam mengingat kegiatan yang pernah dilakukan atau tempat yang pernah di kunjungi.

3. Sistem GPSremember IU90 ini akan berhasil memunculkan pesan jika pesan yang di inputkan (add kegiatan) dilakukan satu hari sebelumnya dan akan memunculkan pesan sekali dalam sehari.

4. Sistem GPSremember IU90 ini akan gagal memunculkan pesan jika user menonaktifkan GPS dan menonaktifkan sistem. 


\section{Saran}

Dari beberapa kesimpulan dan analisa sistem, didapatkan saran-saran yang berguna untuk pengembangan dari aplikasi ini selanjutnya.

1. Penambahan data-data baru serta informasi-informasi lain sangat perlu untuk memperbaiki aplikasi.

2. Sistem ini sebaiknya di terapkan dalam platform lainnya seperti symbian sehingga dapat diakses dari berbagai tipe handphone selain android.

3. Aplikasi GPSremember IU90 ini masih butuh perbaikan serius demi kesempurnaan sistem baik dalam kecepatan memproses data maupun sistem lain agar memperkecil terjadinya error.

\section{Daftar Pustaka}

Ardiansyah, Firdan, 2011, Pengenalan Dasar Android Programming, Biraynara, Depok, Jakarta.

Amiral, Muhammad, 2011, Aplikasi Pengingat Sholat dan Arah Kiblat Menggunakan GPS Berbasis Android 1.6, Infomatika, Institut Teknologi, Banten.

Friesen, Jeff, 2010, Learn Java For Android Development, Pro Android, Apress.

Mulyadi. 2010, Membuat Aplikasi untuk Android, Multimedia Center Publishing, Yogyakarta.

Pratama, Widianto, 2011, Tutorial Android Programming, Universitas Gunadarma.

Sihombing Evalin Marta Damayanti, Kususma Guntur Prabawa dan Kusmayadi Hendra, 2011, Pembangunan Aplikasi Sistem Informasi Dosen Politeknik Telkom Pada Smartphone Berbasis Android, Jurnal Courseware Politeknik Telkom, Bandung.

Anonim, 2010, Android Progamming, http://developer.android.com/ Di akses pada tanggal 20 April 2012.

Google, IO, 2012, Android Anatomy and Physiologi, http://sites.google.com/site/io/anatomy-physiology-of-an-Android. Diakses tanggal 04 Juni 2012.

Haryanto, Agus 2011, Tutorial Android Menampilakan Lokasi GPS pada Google Maps, http://agusharyanto.net/wordpress/?p=480, Diakses tanggal 20 Mei 2012.

Nugraha, 2012, Mengubah Kordinat Latitude dan Logitude. http://mtnugraha.wordpress.com/2011/11/07/mengubah-koordinat-geographiclatitudelongitude/\# comment-983, Diakses tanggal 05 Juli 2012

Haryanto, Agus 2012, Belajar Android Membuat Marker dan Infowindow di Google Maps, http://agusharyanto.net/wordpress/?p=291, Diakses tanggal 29 Mei 2012.

Nugraha, 2012, Mengubah Koordinat Geographic Latitudu dan Longitude, http://mtnugraha.wordpress.com/2011/11/07/mengubah-koordinat-geographiclatitudelongitude/, Diakses tanggal 27 Juli 2012.

Zuhdi, Mohd, 2012, Sistem Koordinat Geografik, www.angelfire.com/mo/zuhdi/Kuliah2.pdf , Diakses tanggal 13 Agustus 2012. 
Indra Usmanan, Sumarsono, Dwi Nugraheny 